\title{
A INFERÊNCIA ANALÓGICA. UM DEBATE ENTRE CHRISTIAN Selle e MarCuS Herz NAS PÁGINAS do MENSÁRIO BERLINENSE
}

THE ANALOGICAL INFERENCE. A DEBATE BETWEEN CHRISTIAN SELLE AND MARCUS HERZ IN THE PAGES OF THE BERLINER MONATSSCHRIFT

\author{
OLIVER TOLLE ${ }^{1}$ \\ Universidade de São Paulo (USP) - Brasil \\ oliver.tolle@gmail.com
}

\begin{abstract}
RESUMO: O presente artigo tem por objetivo contrapor duas posições diferentes sobre a relação de causa e efeito formuladas alguns anos depois da publicação da Crítica da Razão Pura de Kant, a partir da análise de uma série de artigos de C.G. Selle e M. Herz publicados na revista Mensário Berlinense. A despeito do caráter pontual e pouco detalhado do tratamento dispensado à questão pelos autores, o interesse aqui é mostrar que a compreensão de conceitos como inferência causal, analogia e demonstração está longe de ser uma unanimidade, principalmente quando se trata de satisfazer as necessidades mais pragmáticas de ciências como a medicina.
\end{abstract}

PALAVRAS-CHAVE: Filosofia alemã. Causalidade. Analogia. Inferência.

ABSTRACT: The purpose of this article is to oppose two different positions on the cause and effect relationship formulated a few years after the publication of Kant's Critique of Pure Reason from the analysis of a series of articles by C.G. Selle and M. Herz published in Berlinische Monatsschrift magazine. Despite the punctual and not very detailed character of the treatment given to the question by the authors, the interest here is to show that the understanding of concepts such as causal inference, analogy and demonstration is far from being unanimous, especially when it comes to meeting the most pragmatic needs of sciences like medicine.

KEYWORDS: German Philosophy. Causality, Analogy, Inference.

Segundo a compreensão de muitas pessoas, o que o xadrez é para a sociedade, a metafísica é para a organização geral do homem: um passatempo para cabeças pensantes.

Selle

\footnotetext{
${ }^{1}$ Professor livre-docente da Universidade de São Paulo (USP).
} 
Encontra-se um debate entre Christian Gottlieb Selle e Marcus Herz, ambos médicos praticantes devotados à especulação filosófica, nas páginas da revista Mensário Berlinense do ano de $1784 .^{2}$ Estava em questão o significado e a validade da inferência analógica, conforme propõe Selle no seu primeiro artigo. ${ }^{3}$ Esse debate, que coloca frente a frente perspectivas conceituais e terminológicas diferentes, reproduz em menor escala as tensões profundas que o esforço de superação das velhas questões metafísico-escolásticas não foi capaz de suprimir completamente nas décadas intermediárias do século XVIII, e que dizem respeito a promessas e expectativas geradas pela nova ordem dos argumentos oferecida pela virada crítica. Ele também permite vislumbrar alguns aspectos-chave do choque entre a filosofia transcendental de Kant e o materialismo de Selle, embora a dimensão correta da sua efetiva importância e dos protagonistas envolvidos ainda aguarde elucidação. ${ }^{4}$

Se o empirismo e materialismo filosóficos de Selle parecem evidentes, ${ }^{5}$ eles adquirem uma feição muito particular em seus escritos, o que obscurece tentativas de associá-lo a outras correntes de pensamento. Mas já é possível identificar uma linha mestra em seus argumentos: para ele, a filosofia de sua época parecia ter sucumbido mais uma vez à força sedutora da abstração em detrimento da observação empírica. Como explica a Kant em carta de 29 de dezembro de 1787, Selle estava empenhado "em escrever uma metafísica (conceitos originários etc.), que consistisse apenas de conceitos empíricos universalizados", e ele se sentia decepcionado de que "o primeiro filósofo da Alemanha", isto é, o próprio Kant, "tivesse dado um golpe mortal na questão da experiência, que ainda não estava inteiramente de posse de suas prerrogativas", de modo que tinha a impressão de que "a conversa fiada [da velha filosofia] com conceitos idênticos ganhara de novo espaço de manobra" (KANT, AA X, p. 517). Isso ajuda a explicar o interesse de Selle pelo problema da inferência em 1784 e também indica que já estava preparado para o debate, não se tratando portanto de um mero arroubo momentâneo, como pode parecer a partir de algumas imprecisões conceituais de seus artigos de 1784 no Mensário Berlinense.

A objeção que Herz apresenta no número seguinte da revista também não permite considerá-la como uma tomada de posição teórica em sentido estrito, em

\footnotetext{
${ }^{2}$ Christian Gottlieb Selle (1748-1800), médico e filósofo alemão, membro da Sociedade das quartasfeiras e da Academia Real de Ciências de Berlim. Foi o médico oficial de Frederico, o Grande, de Frederico Guilherme II e Frederico Guilherme III. Em vida, foi um dos oponentes mais famosos da filosofia de Immanuel Kant, ao qual todavia trata com notável deferência em seus artigos e obras. Marcus Herz (1747-1803), também médico e filósofo alemão, fez parte do círculo dos Aufklärer de Berlim. Na juventude, foi aluno de Kant em Königsberg. Assim como Selle, é presença constante no Mensário Berlinense.

3 "Da inferência analógica" (SELLE, ago/1784). A tradução integral dos artigos que compõem o debate se encontra reproduzida no final do presente artigo.

${ }^{4}$ Uma análise mais detalhada dessa questão se encontra em BEISER, 1987, pp. 170-80.

5 "Se entendemos pelo conceito de 'materialismo' a doutrina da redução do espiritual ao corpóreo, do abstrato ao concreto e, além disso, do formal ao material, então a doutrina filosófica do médico Christian Gottlieb Selle deve seguramente ser classificada sob esse conceito. [...] Se entendemos pelo conceito "empirismo" a afirmação descompromissada do primado da experiência sensível em qualquer conhecimento, que por isso só pode ser adquirido indutivamente com base nos dados fornecidos, então a filosofia de Selle deve ser caracterizada rigorosamente como "empirista"" (MOTTA, 2011, p. 73).
} 
virtude tanto de sua brevidade como de sua intenção disciplinadora. Mas ela cumpre com a função de exigir de Selle uma melhor explicitação de seus argumentos. A conhecida filiação de Herz à filosofia kantiana, que já pode ser identificada em sua obra Considerações sobre a metafísica especulativa de 1771, deve ser tratada com cuidado. Os seus estudos sobre vertigem de 1786 e sobre física experimental de 1787 dão a entender que a ordem de preocupações no momento são mais práticas do que teóricas. Nesse sentido, conjecturas que ultrapassam o caráter pontual da discussão devem ser, por ora, evitadas.

No primeiro artigo, Selle claramente dá a entender que toma a inferência analógica como mera associação causal: "A inferência analógica não nos permite mais que o seguinte: Coisas que têm causa semelhante também têm efeito semelhante, e inversamente" (SELLE, 8/1784, p. 186). Ao propor essa definição, ele não só parece se afastar do significado mais ordinário de analogia - raciocínio a partir de semelhanças (e não necessariamente de relações de causa e efeito), tomada de empréstimo da matemática e que visa facilitar a compreensão de uma relação $a-b$ por meio de outra relação $c-d$, onde $a-b$ não tem via de regra algo em comum com $c$ - $d$-, como eleva a analogia, ao lado da equação (segundo ele, o procedimento por excelência de todo conhecimento matemático), à condição de principal instrumento da razão. A rebeldia de Selle não termina com esse embaralhamento dos termos. Tudo seria mais fácil se apenas estivesse dando nomes novos a coisas antigas. Ao identificar analogia com relação de causa e efeito, como observa Herz em seu artigo de resposta, Selle parece querer subtrair do conhecimento aquele critério que lhe garantia legitimidade: a capacidade de explicar os motivos de uma determinada causa produzir determinado efeito.

Para explicar o que entende por raciocínio analógico, Selle fornece de início o exemplo simples de um raciocínio que considera falso: se uma coisa tem as características $c, d, e, f$, ao reconhecer em outra coisa as características $c, d$, $e$, estamos legitimados a afirmar que ela também tem $f$. Ora, tudo indica que Selle não apresenta mais do que um falso silogismo, que pode facilmente ser resolvido no âmbito da lógica. Sem dúvida, essa falta de cuidado ou mesmo equívoco causa confusão no leitor. Mas o problema a que ele se refere ganha uma forma mais definida quando o aplica a uma situação concreta. Ele recorre a uma comparação entre o sulfato de sódio e o sulfato de potássio, duas substâncias químicas compostas de um ácido e um álcali, e que tem em comum o ácido ser sulfúrico e de origem mineral. Fica a questão de saber se, porque o álcali do sulfato de sódio é sabidamente de origem vegetal, posso afirmar também o mesmo para o sulfato de potássio. A resposta é negativa, porque neste caso a experiência diz que o álcali é de origem mineral. Assim, o que era antes um problema lógico, passa a ser ao mesmo tempo também um problema empírico. Embora não estejamos legitimados a afirmar que, porque o sulfato de sódio tem um álcali vegetal, o sulfato de potássio também deve ter um álcali vegetal, só podemos, com base nesses dados, saber se é mineral ou vegetal por meio da experiência. A partir disso, como vimos, Selle defende a sua posição: "A inferência analógica se funda por isso numa relação causal, e não pode de modo algum ocorrer sem ela" (SELLE, 8/1784, p. 186). Tudo 
indica que ele entende por relação causal pura e simplesmente a relação entre características observada empiricamente.

A objeção de Herz torna tudo ainda mais intrigante. Ele observa que o raciocínio analógico está fundado sobretudo na expectativa que tenho de encontrar em objetos semelhantes comportamentos semelhantes, e que se encontro repetidas vezes nos objetos $a, b, c, d$, as características $e, f, g, h, x$, ao me deparar com o objeto $k$, que tem as características $e, f, g, h$, espero naturalmente encontrar também nele a característica $x$. Mas essa expectativa, continua Herz, ainda não constitui um conhecimento da relação de causa e efeito entre os objetos e suas características. Trata-se apenas de uma pressuposição e não de um conhecimento demonstrado. Só posso demonstrar a necessidade da presença das características se conheço o porquê da relação de causa e efeito. Mas na hora de dar o golpe final, Herz recorre a alguns exemplos que se mostrarão pouco satisfatórios para Selle. O primeiro deles é extraído da geometria. Se, diante de diversos triângulos retângulos, não conheço o teorema de Pitágoras, não tenho como garantir que a relação entre os lados e a hipotenusa se manterá constante em cada um deles. Sou obrigado então a recorrer à analogia, que contudo nesse caso se mostra limitada para fazer previsões, não me permitindo senão fazer pressuposições, fadadas na maioria das vezes ao fracasso. Apenas o conhecimento das relações causais que estabelecem a natureza do triângulo podem garantir meu êxito.

Herz continua a sua resposta em tom conciliatório. Retomando a oposição leibniz-wollfiana entre conhecimento fundado na probabilidade e conhecimento fundado na demonstração, ele observa que o conhecimento analógico só pode ser do primeiro tipo e que ele se aplica a todas as coisas que observamos sem sermos capazes de identificar as suas diferenças ocultas. Para isso, ele se vale de um segundo exemplo. Se observo uma rosa e anoto todas as suas características, isso não significa que ao encontrar as mesmas características em outra planta, ela necessariamente exalará o mesmo perfume característico da rosa. Sem dúvida, graças à constância dos objetos materiais, terei a expectativa de que isso ocorra. Mas é algo apenas provável. Portanto, só pode se tratar de um conhecimento fundado na analogia.

Com isso, Herz acaba por dar argumentos ao seu oponente. Ele apenas associou a inferência analógica a observações empíricas e a demonstração à matemática, no momento em que Selle queria justamente tratar da certeza da demonstração quando aplicada à experiência. A réplica de Selle não tardará a aparecer. Dois meses depois vem a lume o artigo "Definição mais precisa da inferência analógica" no número de outubro da revista. Ali fica claro que Selle não pretende enfrentar o problema da inferência causal nos termos de Hume - e nem mesmo da solução kantiana, como explicará posteriormente em seus Princípios da Filosofia Pura, de 1788 -; para ele, essas querelas filosóficas pecam pelo excesso de abstração e perdem de vista que a associação causal decorre não do que atribuímos aos objetos físicos, mas daquilo que eles nos informam por meio da experiência. 
Quando, contudo, duas coisas se encontram em associação causal? - Uma reposta muito geral e transcendente para essa pergunta não me atrevo a dar. Por um lado, sabe-se com que sutis razões Hume filosofou sobre essa associação; e se sabe, por outro lado, muito bem que há causas e efeitos no mundo. De fato, não é nem a mera conjunção nem a mera sucessão que nos permite concluir sem engano sobre a associação causal. E apesar disso ninguém negará que temos a maior certeza física de milhares e milhares de associações causais (SELLE, 10/1784, p. 337).

$\mathrm{O}$ argumento de Herz de que a analogia consiste na mera expectativa de que, se estamos habituados a encontrar na experiência as características $c, d, e, f$, $x$ em um objeto A, encontraremos também a característica $x$ em um objeto B depois de já ter verificado que possui $c, d, e, f$, não possui, para Selle, muita utilidade. Ele considera que não há nenhuma analogia ali, apenas um erro grosseiro de raciocínio. A experiência mostra que a constância do mundo físico anda de mãos dadas com a variedade de combinações das características que encontramos nele, e que, portanto, não se pode reduzir uma à outra:

Se A tem $e, f, g, h, x$, e B tem $e, f, g, h$, então não estou legitimado de modo algum a tirar conclusões ou fazer pressuposições de que, por isso, B também terá $x$. Essa seria uma inferência e pressuposição sem fundamento, que poderia aplicar apenas com muito imprecisão, e mil vezes me enganaria. $\mathrm{O}$ incerto e enganoso de tal inferência se multiplica na medida em que as coisas variam umas em relação às outras nas suas características; e incorreríamos no perigo de perder todas as differentia specifica, se permitíssemos tal inferência. Porque duas coisas, que tem três partes em comum, deveriam por isso também coincidir em quatro partes? (SELLE, 1784, p. 336).

Embora a disputa esteja longe de ser resolvida neste breve debate, ela indica que os conceitos de inferência causal, analogia e demonstração ainda resistem a uma desejável acomodação. Se os modelos matemático e lógico da demonstração parecem ser uma referência indispensável para a compreensão dos fenômenos físicos e servem de expediente didático-pedagógico para explicar a capacidade das ciências da natureza de penetrar nos mistérios do mundo material, a sua aplicabilidade permanece restrita, principalmente quando se trata de abarcar a diversidade de conhecimentos empíricos com que lidamos sob o signo da certeza.

$* * *$

Em sua obra Princípios da filosofia pura, publicada quatro anos depois dos artigos, Selle apresenta os fundamentos de seu pensamento e, principalmente, formula de maneira mais consistente sua crítica à filosofia transcendental, que para ele repetia em essência o costume metafísico de se esquivar da observação empírica e da força inescapável de suas evidências para se refugiar na especulação. Para ele, essa fragilidade da metafísica deriva da sua pretensiosa crença de que, por estar apoiada no princípio de contradição, um conhecimento governado 
unicamente pela razão, ela teria autonomia e legitimidade para lidar com os seus conceitos abstratos, independentemente da experiência. Esse equívoco nasce da identificação entre lógica e metafísica:

Sem conceitos sensíveis não são possíveis quaisquer conceitos do entendimento, porque eles se referem à relação das coisas fornecidas pelos sentidos, e mesmo a relação das relações tem de ser referida sempre a coisas, as quais, por sua vez, têm de ser deduzidas ou das coisas conhecidas por meio da experiência ou dos conceitos e signos dessas coisas, já que não existem outras coisas [Dingen] e não pode haver nenhuma relação entre não-coisas [Undingen]. Por isso, a filosofia pura é uma mera abstração das coisas utilizadas e de modo algum, como se supõe, da origem suprassensível, pois então seria necessário querer nomear de modo suprassensível tudo que foi deduzido e é compartilhado [Gemeinsam] entre o sensível e os signos do mesmo.

O conhecimento racional das conexões físicas constitui, por isso, a parte essencial da filosofia. O conhecimento racional das conexões lógicas perde toda a sua utilidade e valor sem a aplicação a conexões físicas, assim como todo conhecimento das conexões lógicas é vazio e sem conteúdo sem relação a conexões físicas.

A negligência dessa diferença entre filosofia pura e aplicada contém a maior parte das razões dos enganos nessa ciência. Confunde-se a parte aplicada da lógica com metafísica e não se quer, por isso, saber de nenhuma outra filosofia, senão aquela que se ocupa de conexões lógicas. Por isso, se queria demonstrar todas as verdades metafísicas por meio do princípio de contradição, e este foi um empreendimento vão, porque as premissas que têm de ser inferidas por meio da razão teriam de ser dadas na filosofia pela experiência (SELLE, 1788, pp. 12-13).

Se a metafísica, como procedimento que resulta da abstração e generalização de características particulares observadas empiricamente, é um aspecto inalienável da filosofia, ela precisa contudo permanecer ancorada justamente naquilo que pretendia de início: conhecer o mundo dos objetos, o que só pode ocorrer de maneira fundamentada por meio de analogias - quer dizer, no sentido dado por Selle: reconhecer semelhanças entre as características dos objetos e as suas relações umas com as outras, as quais servem de amparo para a noção de nexo causal: "De dois fenômenos diversos, que são de momentos diversos mas jamais um sem o outro, dizemos que se comportam como causa e efeito ou se encontram num nexo causal" (SELLE, 1788, p. 36). Nesse sentido, a força da demonstração lógica e matemática deve ser usada com parcimônia, porque ela se caracteriza por equacionar relações, isto é, por encontrar e estabelecer equivalências entre os termos. Um tipo de conhecimento que privilegia a forma em detrimento do conteúdo:

Por isso, todo o uso lógico da razão se baseia na equação, assim como o uso físico e metafísico se baseiam na analogia. Na filosofia pura e na matemática só têm lugar equivalências, assim como uma metafísica sem argumentos analógicos teria de ser e permanecer sem qualquer conteúdo (SELLE, 1788, p. 55). 
Selle não subestima, todavia, o papel da faculdade da razão na obtenção de conhecimento. Sem dúvida, é a ela que se deve a descoberta das leis do objetivo e a capacidade de ir além da particularidade dos fenômenos. As leis do conhecimento humano que resultam desse processo devem, todavia, ser tomadas apenas como o que são: um subproduto dessa busca. A incapacidade de penetrar na essência das coisas não pode se converter em motivo para sacrificá-las em favor de uma filosofia meramente especulativa.

Por isso, a experiência é o único caminho que a razão deve percorrer na procura da verdade. E essa razão não é senão a faculdade de tornar as experiências em objetos do conhecimento. Por meio de comparação, abstração e generalização da matéria fornecida pela experiência surgem puras verdades da razão, ou as leis do conhecimento humano, das quais jamais nos poderíamos nos tornar conscientes sem a experiência e que são deduzidas da experiência. Equação e analogia são os instrumentos necessários e indispensáveis da razão, assim como ambos necessariamente pressupõem pensamentos e fenômenos como objetos dados. Experiência e razão são as duas instâncias de aquisição do nosso conhecimento (SELLE, 1788, p. 24).

Além das evidentes referências de Selle a Locke, o seu interesse pela metafísica parece mais alinhado a algumas linhas argumentativas da Escola de Wolff, especialmente de Gottsched, que na sua Sabedoria mundana de 1733 também exigia que todo conhecimento abstrato obedecesse rigorosamente à regra de que as suas escolhas terminológicas e conceituais não se afastassem do compromisso com a descrição e definição dos conteúdos da experiência. Isso fica ainda mais claro quando Selle reproduz a expectativa de que, mantida essa regra, a filosofia chegará no futuro a apagar a distância entre particular e universal:

\begin{abstract}
Quando em algum momento a verdade importante for reconhecida de que não há nenhum outro conhecimento senão aquele que é conhecido imediatamente pela experiência ou inferido e concluído de maneira mediada pela razão a partir daquilo que é conhecido pela experiência, quando a linguagem, o meio necessário e indispensável para o raciocínio, for determinada com precisão e correção, e essa destinação da linguagem não for mais confundida com a destinação daquilo para cuja vocação ela propriamente deve servir, então essa diferença deve ser removida - então a filosofia se tornará a mestra benfazeja da verdade, tanto quanto permite a capacidade do espírito humano e requer o desiderato de nossa felicidade na terra (SELLE, 1788, pp. 19-20).
\end{abstract}

Não causa agora mais tanta estranheza Selle considerar a analogia como procedimento por excelência para a obtenção das leis do conhecimento humano. Ao mesmo tempo em que se recusa a entrar no debate sobre a origem da inferência causal posta nos termos humeanos e kantianos, porque de um modo ou de outro ambos enfraquecem a força da evidência empírica, Selle compartilha da demanda

\footnotetext{
${ }^{6}$ GOTTSCHED, 1733.
} 
da sua época de superação da velha metafísica e, principalmente, da necessidade de dissolver o dualismo sujeito e objeto. Chama contudo aqui a atenção o modo como se apropria de um procedimento metafísico, que reconhece na analogia com experiências do mundo dos objetos a única possibilidade de se referir ao supramundano e ao divino e explicá-los, para agora fundamentar a relação entre experiência e razão, produzindo assim uma curiosa metafísica materialista, em que a forma deve ser tão próxima do conteúdo, que praticamente não tem mais sentido diferenciá-los entre si. Como explica Selle, a metafísica não tem como contornar essa exigência, mesmo recorrendo ao auxílio do raciocínio: "Por mais indispensável que o raciocínio lógico seja para a metafísica, nada pode ser descoberto por meio daquilo que tivesse realidade objetiva e existente fora do conhecimento, se não fosse aplicado a associações físicas" (SELLE, 1788, p. 57). ${ }^{7}$

\section{DA INFERÊNCIA ANALÓGICA}

Senhor Professor Selle

(Mensário Berlinense, agosto de 1784, pp. 185-187)

Já observei muitas vezes em escritos de boas mentes, que eles possuem um conceito falso de inferência analógica. Permitam-me, portanto, corrigi-lo aqui.

Não podemos inferir: quando a tem as características $c, d, e, f$, e $b$ tem as características $c, d$, e, então ele também tem $f$. - Tal inferência só pode ser aplicada com imprecisão; mas ela é sem fundamento, como ficará claro no exemplo a seguir, que extraí da química, porque ela estabelece os caracteres mais determinados.

1. O sulfato de potássio a consiste de um ácido e de um álcali.

2. O ácido é de espécie mineral.

3. O ácido é sulfúrico.

4. O álcali é de espécie vegetal.

Se examinarmos um sal sulfato de sódio $b$, e descobrirmos

1. Que ele consiste de um ácido e de um álcali;

2. Que o ácido é de espécie mineral;

3. Que o ácido é sulfúrico.

Estaremos legitimados a inferir que o álcali é de espécie vegetal? Isso causaria bastante confusão, porque se trata de um álcali mineral. Espero que esse exemplo seja suficiente para mostrar a falta de fundamento de tal inferência.

\footnotetext{
${ }^{7}$ Passagem que em muitos aspectos parece tentar corrigir a máxima kantiana de que só podemos nos aproximar de objetos suprassensíveis graças à realização de analogias com a experiência, as quais, todavia, não nos permitem conhecimentos de coisas em si. O quanto Selle procede como reformador da filosofia kantiana, é assunto para futura consideração.
} 
A inferência analógica não nos permite mais do que o seguinte:

Coisas que têm causa semelhante também têm efeito semelhante, e viceversa.

Quando descubro que um corpo a, por exemplo, o sal amargo, tem efeito laxante, então concluo que um corpo $b$, caso seja composto de partes semelhantes numa relação semelhante e de modo semelhantemente mais solto e profundo, ele também terá efeito semelhante.

Por isso, a inferência analógica se funda numa relação causal, e não pode de modo algum ocorrer sem ela.

De resto, não quero aqui me aprofundar na natureza dessa inferência. É suficiente saber que a experiência confirma em todos os lugares a verdade da seguinte máxima: que causas semelhantes produzem efeitos semelhantes e, inversamente, efeitos semelhantes têm causas semelhantes.

Quis justificar essa inferência apenas pelo lado com que a maioria dos meus oponentes parecem ter me atacado.

\section{SOBRE A INFERÊNCIA ANALÓGICA}

\section{Marcus Herz \\ (Mensário Berlinense, setembro de 1784, pp. 246-251)}

No que diz respeito à essência da analogia, não posso ser inteiramente da opinião do meu colega de filosofia, Senhor Professor Selle. ${ }^{8}$ Posso considerar a inferência analógica pelo lado que quiser e descubro sempre que ela não se refere meramente ao nexo causal; apesar disso, ela sempre tem como consequência que, quando encontro, em diferentes objetos $a, b, c, d$, por exemplo, sempre acompanhados das características $e, f, g, h, x$, e me deparo com um objeto estranho $k$, no qual percebo apenas $e, f, g$, $h$, então espero e suponho, enquanto não for convencido do contrário, que ele também terá $x$, sem que eu tenha a necessidade de compreender como a reunião de $e, f, g, h$, é a causa eficiente de $x$. Nisso presumo implicitamente que, porque encontrei tantas vezes $e, f, g, h$, junto com $x$, há provavelmente uma espécie de associação entre eles, a qual torna a sua reunião necessária em toda parte. - Além disso, quando compreendo efetivamente a relação causal entre $e, f, g, h$ e $x$, justamente então não se trata mais de analogia, mas de demonstração: eu não espero, não pressuponho, a presença de $x$ junto a $k$, mas a infiro, sou convencido dela.

Quando desenho para mim um triângulo retângulo e descubro mediante demonstração a priori, que as suas três linhas, a sua delimitação espacial, o seu ângulo reto, são as causas da relação pitagórica da hipotenusa com as outras duas linhas, e afirmo isso depois para todo triângulo retângulo que me ocorrer na

\footnotetext{
${ }^{8}$ Ver edição de agosto, p. 185 (N. do A.).
} 
sequência, então essa afirmação se funda não na analogia, porque esse triângulo esboçado possui essa característica; mas ela se funda igualmente na demonstração, que posso repetir de novo para cada triângulo retângulo; reconheço em cada um deles em particular como e porque possui essa característica. - Caso não conhecesse a demonstração do teorema de Pitágoras, mas soubesse apenas a partir de alguns triângulos retângulos que medi que essa relação entre linhas tem lugar entre eles, então não reconhecerei essa relação na série de todos os triângulos retângulos que me aparecem e não estarei convencido dela, mas a suporei nos triângulos e direi: nesses triângulos encontro todas as características reunidas como naquelas que medi; portanto, também essa característica será encontrada neles, que o quadrado da hipotenusa etc. No primeiro caso, reconheço o nexo causal entre as diferentes características; no último, apenas presumo tal relação entre elas e espero por isso a sua coexistência em toda a parte. - E assim se dá, me parece, em todos os lugares onde concluímos por analogia.

A experiência nos ensina em muitas transformações que possuem as características $e, f, g, h$ - em virtude das quais são chamadas de naturais -, que elas também possuem a característica $x$ e que, a saber, essas transformações ocorrem por meio de uma transição gradual e constante. Quando nos deparamos com uma transformação natural, na qual a experiência nada nos ensina sobre a característica $x$, como, por exemplo, na transformação da vida para a morte, ainda assim julgamos que $x$ corresponde a ela, e na verdade segundo analogia, porque todas as outras transformações naturais também ocorrem de modo constante. Se pudéssemos demonstrar, a partir dessa associação de causa e efeito, que essa transformação corresponde a $x$, então não diríamos que reconhecemos essa característica de modo analógico, mas estaríamos convencidos dela como numa demonstração.

Os defensores do sistema evolutivo para a geração animal se apoiam, entre outros, no modo de geração vegetal, segundo o qual o futuro crescimento já está manifestamente presente na semente, julgando da seguinte maneira: como ambos [os modos da geração animal e vegetal] são efeitos naturais bastante semelhantes, também coincidirão no fato de que a criatura futura é meramente um desenvolvimento ulterior. Aqui não há vestígio algum de associação causal, mas se trata de pura analogia.

Todas as vezes que vi uma planta com certas características, a saber, com tais folhas, tal cor, tal caule, tal florescência etc., encontrei também nela sempre uma espécie de exalação, que reconheço e distingo por meio do meu olfato e denominamos de perfume de rosas. Tão logo vejo à distância uma planta com as mesmas características, aproximo-me com certa expectativa de encontrar nela também o perfume de rosas.

Aqui como em outros inúmeros exemplos que poderia indicar, a pressuposição da característica $x$ não se funda em reconhecermos as causas que a produzem necessariamente - pois de onde reconhecemos que a cor, as folhas, o caule, a flor da rosa são as causas da exalação do perfume de rosas? Ela pode ser a consequência de uma característica inteiramente diferente e ainda oculta da rosa; ela pode ser também, em vez de ser a consequência, ser justamente a causa das 
demais características, e não podemos concluir a partir da presença dela a das demais; e, em geral, quem reconhece, quem compreende os nexos causais da natureza? - ao contrário: porque vimos tantas vezes $x$ junto a $e, f, g$, $h$, e não é provável que essa reunião se deva a algo incerto, pressupomos que deve ter lugar entre essas características um nexo e, por isso, esperamos $x$ em todos os lugares em que nos deparamos com $e, f, g, h$.

Que essa espécie de argumento esteja muitas vezes ausente, como indica o meu perspicaz colega, é algo que não se discute. Prova disso são as relações naturais entre gêneros e classes, entre subespécies e espécies superiores, nas quais, a despeito da mais alta correspondência das características, encontram-se, contudo, ainda diferenças. Mas isso se deve justamente ao fato de que essa inferência não é convincente, não é demonstrativa, mas apenas um derivado da probabilidade, a qual tantas vez nos engana. A analogia vale apenas até que a experiência nos convença do contrário. Tão logo a experiência nos indique uma única uma transformação natural que ocorre por meio de um salto ou uma planta que possui todas as demais característica da rosa e apesar disso não exala o seu perfume, por exemplo, então o argumento analógico torna irrelevante o processo permanente e constante da natureza ou a conjunção permanente do perfume de rosa com as suas demais características. Enquanto isso não acontece, a analogia sempre se manterá, para cada caso particular, como uma inferência correta. Na medida em que não conheço o sulfato de sódio e tenha diante de mim um sal de que sei que consiste de um ácido e de um álcali e que o sal é de espécie mineral, então a analogia me permitirá pressupor que o álcali ali contido é de espécie vegetal, quer dizer, que que todo o sal neutro é um sulfato de potássio. Mas assim que examino mais precisamente o sal neutro e descubro que é um sal mineral, então cessa a analogia; pois a experiência então me mostra que não há entre as características mencionada nenhum vínculo necessário. E quando me deparo no futuro com um sal neutro, cujo ácido é um ácido sulfúrico, então, no que diz respeito à constituição do álcali, ficarei incerto se é mineral ou vegetal, se o todo é um sulfato de potássio ou um sulfato de sódio.

Consideramos agora muitas coisas como de uma única espécie, as quais, contudo, quando a experiência nos revelar um dia as suas diferenças ocultas, poderão ser decompostas em espécies inteiramente diferentes.

\section{DEFINIÇÃO MAIS PRECISA DA INFERÊNCIA ANALÓGICA}

Senhor Professor Selle

(Mensário Berlinense, outubro de 1784, pp. 334-337)

Se percebo em A $e, f, g, h, x$, e sei que $x$ se encontra necessariamente associado a $e, f, g, h$, concluo: que $\mathrm{B}$, se tem $e, f, g, h$, também possuirá $x$, porque $x$ se encontra em associação necessária $\operatorname{com} e, f, g, h$. Ou, em suma: onde está $e$, $f, g, h$, ali também está $x$. B tem $e, f, g, h$. Por conseguinte tem também $x$. Esse é uma inferência comum. 
Se A tem $e, f, g, h, x$, e sei que $x$ se encontra em associação necessária com $e, f, g, h$, então infiro que $\mathrm{B}$, se possuir a semelhança $\mathrm{Z}$ com $e, f, g, h, \mathrm{Z}$ também terá $x$. Esse é a inferência analógica.

Ambas as inferências são demonstrativas se as premissas forem corretas.

Se A sempre teve $e, f, g, h$, sem que eu saiba se essas cinco partes pertencem necessariamente a A, então pressuponho que A, enquanto permanecer A, também conservará $e, f, g, h, x$, até que seja convencido do contrário. Isso é probabilidade.

Se A tem $e, f, g, h, x$, e B tem $e, f, g$, $h$, então não estou legitimado de modo algum a tirar conclusões ou fazer pressuposições de que, por isso, B também terá $x$. Essa seria uma inferência e pressuposição sem fundamento, que poderia aplicar apenas com muito imprecisão, e mil vezes me enganaria. O incerto e enganoso de tal inferência se multiplica na medida em que as coisas variam umas em relação às outras nas suas características; e incorreríamos no perigo de perder todas as differentia specifica, se permitíssemos tal inferência. Porque duas coisas, que tem três partes em comum, deveriam por isso também coincidir em quatro partes?

No inferir se trata sempre de associação, sem a qual nenhuma inferência do conhecido para o desconhecido é válida. Onde temos certeza dessa associação, então as inferências são demonstrativas; onde ela não é identificada, mas incerta, as inferências são relativamente enganosas, e mais ou menos prováveis.

Essa associação não é nenhuma outra senão a associação causal. Não há nenhum outro motivo para que duas coisas possam estar conectadas uma à outra; essas duas coisas teriam então de constituir propriamente apenas uma coisa e ser diferentes apenas na maneira como as representamos.

Quando, contudo, duas coisas se encontram em associação causal? - Uma resposta muito geral e transcendente para essa pergunta não me atrevo a dar. Por um lado, sabe-se com que sutis razões Hume filosofou sobre essa associação; e se sabe, por outro lado, muito bem que há causas e efeitos no mundo. De fato, não é nem a mera conjunção nem a mera sucessão que nos permite concluir sem engano sobre a associação causal. E apesar disso ninguém negará que temos a maior certeza física de milhares e milhares de associações causais.

\section{REFERÊNCIAS}

BEISER, Frederick C. The Fate of Reason - German Philosophy from Kant to Fichte. Cambridge, Massachusetts, London: Harvard University Press, 1987.

GOTTSCHED, Johann Christian. Erste Gründe der gesamten Weltweisheit, darinn alle Philosophische Wissenschaften in ihrer natürlichen Verknüpfung abgehandelt werden. Leipzig: Verlegts Bernhard Christoph Breitkopfen, 1733.

HERZ, Marcus. Ueber die analogische Schlußart. Berlinische Monatsschrift, v. 9, p. 246-251, 1784. 
KANT, Immanuel. Das Bonner Kant Korpus. Elektronische Edition der Gesammelten Werke Immanuel Kants. Disponível em: https://korpora.zim.uniduisburg-essen.de/kant/

MOTTA, Giuseppe. Evidenzen. Die Abschaffung der Form in Ch. G. Selles Auseinandersetzung mit Kant. Philosophical Readings, v. 3, n. 3, p. 73-77, 2011.

SELLE, Christian Gottlieb. Von der analogischen Schlußart. Berlinische Monatsschrift, v. 8, p. 185-187, 1784.

Nähere Bestimmung der analogischen Schlußart. Berlinische Monatsschrift, v. 10, p. $334-337,1784$.

Versuch eines Beweises, dass es keine reine von der Erfahrung unabhängige Vernunftbegriffe gebe. Berlinische Monatsschrift, v. 12, p. 565-576, 1784. $141,1786$.

Ueber Natur und Offenbarung. Berlinische Monatsschrift, vol. 8, p. 121Grundsätze der reinen Philosophie. Berlin: Hamburg, 1788.

Recebido em: 10-07-2020

Aceito para publicação em: 26-07-20 